\section{Training in Australia}

Sir - Two excellent articles in 1997 give a very useful perspective on training in the UK and USA. ${ }^{1,2}$ As an Irish graduate who has recently returned from a year working as a psychiatrist in Melbourne, Australia, I can recommend the experience to be gained there. Traditionally, the belief has been that doctors go to Australia after their internship to enjoy a year of relaxation (and some work) in the Australian sun. They then return to the UK or Ireland to pursue their intended career. This need not be the case. Psychiatric training in Australia can be incorporated easily into one's career.

There is a shortage of psychiatrists and psychiatric trainees in Australia. This situation is unlikely to change in the near future which augurs well for the Irish doctor wishing to work there. Most of the Australian population live in the urban centres of the coastal regions. This is where most opportunities for training lie. The practice of psychiatry in Australia is similar to Ireland. Melbourne, in the State of Victoria, is a multi-cultural city with a population of three million. In some areas of the city up to $50 \%$ of the population do not speak English as their first language. This gives the trainee experience in transcultural psychiatry not to be found in Ireland. It has an advanced and well-funded system of community psychiatry which includes crisis assessment and treatment teams (CAT teams). Their remit is to assess people in psychiatric crisis and treat them at home wherever possible. Working in a CAT team offers novel and extremely worthwhile experience in acute psychiatry.

For the doctor wishing to arrange a period of training in Australia the first thing to do is to arrange a suitable post. Exchange of trainees between some training schemes in Britain and Australia exist. These schemes prove to be extremely popular. To my knowledge, no equivalent exchange exists between Ireland and Australia. For the Irish trainee, simply writing to consultants or clinical directors in the major centres may pay dividends. However, more effective by far are the contacts made by word of mouth and personal recommendation.

When a post has been offered by a hospital, that hospital will provide sponsorship for an immigration visa, usually an occupational training visa. Limited and specific registration with the relevant Medical Practitioners Board in Australia will be granted upon arrival in the country.

The pre-membership trainee will work in a post which is recognised for training by the Royal College of Australia and New Zealand. A letter from that College to this effect can be presented to the Royal College in London.

The post-membership trainee can arrange one year of overseas training which will count toward the Certificate in Specialist Training. It is better to arrange this when already in a senior registrar/specialist registrar rotation. It is usually possible to arrange a year's absence from a scheme knowing there is a place available upon return.

Salaries between the public system in Australia and Ireland are similar. The cost of living is lower in Australia and the much envied superb quality of life is well known. When leaving Australia I was asked by my clinical director to recommend that my Irish colleagues consider going to Australia. I can do this without hesitation from both a professional and a personal perspective. I am aware that many are attracted by the idea of working in Australia but put off by the perceived difficulties in organisation. There have been a number of articles in the last couple of years which have given detailed information to the prospective trainee. ${ }^{3,4}$ Having completed a year in Australia and returned to work in Britain I can assure anyone who is interested that the difficulties involved in organisation are not great and forgotten by the time of the first barbecue.

\section{Feargal Leonard, MB, Bch, BAO, MRCPsych, Clinical Research Fellow, Department of Psychiatry, Imperial College School of Medicine, Charing Cross Hospital, Fulham Palace $R d$, London W6, England.}

References

1. Lucy JV. Specialist psychiatry training in Britain: an Irish graduate's perspective. Ir J Psych Med 1997; 14(2): 60-2

2. Kirrane R, Serby, M. Residency training in psychiatry in the USA: an Irish graduate's perspective. Ir J Psych Med 1997: 14(2): 62-4.

3. Wilkie A. Australia: Getting there. Psychiat Bull 1996; 20: 558-60. 4. Kisely S. Training manpower and employment in Australia. Psychiat Bull 1993; 17: 669-71.

\section{Re: Suicidal behaviour in children}

Sir - Fifty consecutive children attending a Child and Family clinic were asked to complete a questionnaire on suicidal behaviour.' The children's mothers were assessed for anxiety and depression ${ }^{2}$ as well as neighbourliness. ${ }^{3}$ Eight per cent of the children had made a suicidal attempt, $15 \%$ had thought of killing themselves but had not made an attempt.

No correlation was found between child suicidal behaviour and mother's anxiety, depression or neighbourliness. Children were aged from nine years to 16 years and the suicidal behaviour increased with age. When asked if they knew somebody who had attempted suicide, all the children who had attempted suicide said they did while $60 \%$ of those who had thought about killing themselves said they did and finally $14 \%$ of those with no suicidal behaviour said they knew somebody who had attempted suicide.

A previous Irish study ${ }^{4}$ showed that $6.9 \%$ of female adolescents had suicidal thoughts often. Another Irish study ${ }^{5}$ of nine to 11 year olds showed that $15 \%$ thought that life was not worth living most of the time while $18.8 \%$ thought that their life was not worth living some of the time.

\section{Michael Fitzgerald, Henry Marsh Professor in Child \&o Adolescent Psychiatry Department of Psychiatry, Trinity College, Dublin 2, Ireland.}

References

1. Harkavy Friedman J, Anis G, Boek M, Di Fiore J. Prevalence of specific 
suicide behaviours in a high school sample. Am J Psychiar 1987; 144(9): 1203-6.

2. Zigmond AS, Snaith RP. The hospital anxiety and depression scale. Acta Psychiatrica Scand 1983; 67: 361-3.

3. Wallin PA, Guttman. Scale for measuring women's neighbourliness. Am J Sociology $1951 ; 46: 243-6$.

4. Brown K, Fitzgerald M, Kinsella A. A prevalence of psychological distress in Irish female adolescents. J Adolescence 1990; 13(4): 341-50.

5. Murphy M, Fitzgerald M, Kinsella A, Cullen M. A study of emotions and behaviour in children attending a normal school in an urban area. Ir J Med Sci 1989; 158: 117-47.

\section{Atypical presentation of frontal lobe tumour - a cautionary tale}

Sir - A case is described of a frontal lobe brain tumour presenting as a slow deterioration in affect, personality and living skills. It is compared with other studies and reviews from the literature and the actual typicality of so-called 'typical' symptoms and signs is questioned. Finally, the implications for investigation and continuing care in atypical cases is reviewed.

Classical, intracranial frontal lobe tumours in elderly patients present with a relatively short history of deficits in behaviour, mental state and cognitive function, with progressive neurological signs. This has previously been reviewed by Fulton et al. ${ }^{1}$ The authors presented 14 patients with intellectual and behavioural deterioration coupled with failures in self-care occurring over a few weeks.

Computed tomography (CT) scanning showed frontal or bifrontal tumours in 13 cases and one case of occipital lobe tumour. The authors stressed the importance of CT scanning of elderly patients with a relatively short history of confusion or intellectual failure. Most patients in their study (12 of 14) also had early demonstrable neurological signs and the importance of detailed neurological examination was emphasised.

This case report describes a quite different presentation, namely that of a far more insidious deterioration of affect, personality and living skills occurring in the absence (at least initially) of hard neurological signs, but in which CT scan was 0 (less revealing in terms of diagnosis and prognosis).

GM, a 68 year old former accountant was initially referred as an outpatient with an eight-month history of low mood, fatigue and a constant 'band-like' headache unaccompanied by nausea, vomiting, or blurring of vision. He described early-morning wakening, diurnal variation of mood and loss of interest in his normal pursuits. During this period, his thinking had become morbidly introspective, with ruminations about the death of his mother 17 years previously and about his own mortality.

Born locally, he remembered being a happy and healthy child, although he felt his mother had been overprotective towards him. He had no siblings. Following a successful scholastic career, he worked initially as a bank teller and subsequently gained entry to the accountancy profession. Here, he remained until retirement aged 64 . It was noted that during his latter six years with the firm his personal appearance, particularly his smartness and cleanliness, deteriorated markedly. It was felt he no longer 'fitted' the image of the firm and he was moved initially to part-time working and ultimately to early retirement.

His father died in 1958 and GM then lived with his mother until her entry into a residential home in 1979 and her death a few months later aged 93 . There is no family psychiatric history. A lifelong non-smoker and teetotaller, he always found social and personal relationships difficult and never married.

Following an episode of mumps orchitis aged 13, he became preoccupied with his health but appears to have had no further physical illnesses. He received inpatient treatment for depression in 1970 . It was noted at the time that he was "compliant, obsessional and fitted in easily with ward routine". He was treated with electroconvulsive therapy and made a good recovery.

At initial outpatient consultation for his present illness, his appearance was striking. He was unkempt, clearly unwashed and heavily bearded. Although highly articulate and showing a dry sense of humour, he was apathetic and his mood state was one of deep unhappiness. He showed no suicidal or psychotic thinking and cognitive testing revealed no abnormality. A diagnosis of depression was made and he was started on paroxetine $20 \mathrm{mg}$ with arrangements for follow-up investigations and review.

A social services home visit was arranged and found him to be living in 'indescribable squalor' with evidence of very poor self-care and months of domestic and bodily waste piled in each room. He was admitted voluntarily to the psychogeriatric assessment ward.

Physical examination and serum investigations revealed no abnormality. CT brain scan, however, showed a mixed density mass in the right frontal lobe with calcification. The right lateral ventricle was slightly compressed. An urgent neurosurgical consultation and Magnetic Resonance Imaging (MRI) scan strongly favoured a diagnosis of "large slow-growing frontal meningioma". The neurosurgeon advised against operation due to size and location of tumour.

The patient's mood over subsequent weeks remained one of depression. He made little response to different antidepressants and began developing intrusive, obsessional worries about dirt and contamination. Despite discussions with staff regarding diagnosis he showed difficulty in comprehension and acceptance and firmly believed he would recover. He received supportive psychotherapy from a clinical psychologist which gradually helped him accept his diagnosis and plan for the future. Four months after admission he remained fully cognitively intact, scoring 27/30 on Mini-Mental State Examination (Folstein et al). ${ }^{2}$ As the tumour progressed he developed a left-sided hemiplegia, urinary incontinence and dysarthria - with no response to steroids. A repeat CT scan confirmed a midline shift and falcine herniation consistent with tumour progression.

These developments necessitated a package of terminal nursing care with ongoing physical and psychological support to ensure maximal comfort and freedom from distress. During this period, many of his depressive symptoms lifted and he began drawing up his will and discussing aspects of his care eg. whether to enter a hospice. Psychological support was also available to staff as they nursed a dying patient whom they had by now known for several months.

Avery $^{3}$ divides the symptoms of frontal lobe tumour into: (a) neurological, (b) psychological ie. causally related to 